\title{
Measuring Porosity of Anodes in Solid Oxide Fuel Cell (SOFC) through Water Archimedeans Porosimetry
}

\author{
Syed Mubashar Hassan', Syed Ali Hasnain² \\ ${ }^{1}$ School of Engineering and Built Environment, Edinburgh Napier University, Edinburgh, UK \\ ${ }^{2}$ Centre of Excellence in Sustainable Building Design, School of Energy, Geosciences, Infrastructure \& Society, \\ Heriot-Watt University, Edinburgh, UK \\ Email: mubashar naqvi@live.co.uk
}

Received 26 May 2015; accepted 22 June 2015; published 25 June 2015

Copyright (C) 2015 by authors and Scientific Research Publishing Inc.

This work is licensed under the Creative Commons Attribution International License (CC BY).

http://creativecommons.org/licenses/by/4.0/

(c) (i) Open Access

\section{Abstract}

The present research is aimed to measure the porosity of anodes in solid oxide fuel cell through water Archimedeans method. There are various alternatives available to replace fossil fuel cells like nuclear power, wind energy, solar energy, bio fuel, and geothermal and fuel cells. Among all the alternatives of fossil fuel, one form of energy production that stands out from the rest and promises a sustainable future energy is fuel cell. Moreover, it offers many advantages in contrast to other forms of energy generation. An Archimedean approach for water immersion porosimetry is carried out. Some of the results are beyond rational limits, and given negative and sometime above 100 percent porosity. The reasons for these unacceptable results are either due to water ingress into the sample or the sample turns into buoyant due to air in the cling film. The results from Archimedean porosimetry should only be used qualitatively due to errors associated with the results. It is also noted that Archimedean porosimetry is not the ideal technique for measuring the porosity of coated samples. It is suggested that larger samples should be analyzed that will help to minimize the weighing errors.

\section{Keywords}

Solid Oxide, Fuel Cell, Porosity, Anodes, Archimedeans

\section{Introduction}

Increasing energy prices is a testimony to the fact that as we already are facing energy shortages, and the worst 
is still to come because according to a UN report the world population will be 10.5 billion in 2050 [1] [2] compared with 6.5 billion now and in 2040 we will be requiring double the energy compared with what we are using today, and our need for electricity will double by 2030 [3]. Living conditions and life standards are improving throughout the world especially in the developing and underdeveloped countries. Therefore, if the entire world has same living conditions as Britain then we will be requiring energy resources (non-renewable) equivalent to three earths [4]. There are various alternatives available to replace fossil fuel cells like nuclear power, wind energy, solar energy, bio fuel, and geothermal and fuel cells. Among all the alternatives of fossil fuel, one form of energy production that stands out from the rest and promises a sustainable energy future is fuel cell. Moreover, it offers many advantages in contrast to other forms of energy resource [5].

\section{Solid Oxide Fuel Cells (SOFC) in Relation to Porosity of Anodes}

SOFC is high temperature fuel cell which uses solid material as electrolyte for their energy production. The operating temperature for the $\mathrm{SOFC}$ is $800^{\circ} \mathrm{C}-1000^{\circ} \mathrm{C}$. The high temperature is advantageous as it generates high quality exhaust heat which is used for cogeneration, but on the other hand, high temperature also limits the use of most of the materials [6]. So, scientist have tried and succeeded in bringing down the temperature to $600^{\circ} \mathrm{C}$ to $800^{\circ} \mathrm{C}$, thus classifying them as intermediate temperature solid oxide fuel cells (ITSOFC) and high temperature solid oxide fuel cells (HTSOFC) [7] [8]. Though low temperature brought some material flexibility, it also decreased the electrode kinetics and electrolyte conductivity which limited their use. So, HTSOFC still remains more prevalent [9]. SOFC is the most likely candidate for the commercialization of fuel cells because of the advantages they offer.

- SOFC is highly efficient, the efficiency of fuel cell is not dependent on the Carnot cycle of heat engine and their combined heat and electric efficiency is higher than all other types of fuel cells.

- SOFC is tolerant to impurities where CO is used without damaging the working of SOFC, unlike other fuel cells where carbon monoxide (CO) acts as a poison.

- Fuel flexibility is the single biggest advantage of SOFC because of such a high temperature; a great number of hydrogen containing compounds can be used as fuels which are internally reformed by the unit.

- As SOFC uses solid electrolyte, there are no moving parts involved for the circulation of electrolyte. So, it is noise pollution free.

- Design simplicity and ability to work without expensive catalysts are the few of the other advantages which make SOFC most probable commercial reality [10] [11].

\section{Material \& Methods}

In this section details of the experimental work carried out during the project is discussed. This includes information about the sample, calculations, instruments and chemical used.

Health and safety issues involved and problem faced during experimentation are also discussed briefly. In the first part sample naming along with sample preparation for the experiments are presented. Archimedean approach for water immersion porosimetry are carried out, details along with calculations are discussed.

\subsection{Sample Information}

The samples to be analyzed are the alumina coated Ni/YSZ anodes which are manufactured by electro less deposition by varying four variables (Table 1 ).

Each variable has two variations (level). The purpose of all of this is to analyze the effect of these variables on the porosity of the anode. One relatively simple way of checking the effect of variables on the final output is one variable at time technique (OVAT), but according to (Jiju, 2003) OVAT technique is not a reliable one, because some time combination of variables give different results from the ones when they are individually analyzed. Let's suppose that by keeping all the other three variables constant increase in particle size increases the porosity of the anodes, but it may happen that by increasing $\mathrm{pH}$, increase in particle size actually decreased the porosity of anodes. so while manufacturing anodes the knowledge of design of experiment (DOE) was kept in mind and OVAT technique is avoided and all the sixteen possible combinations from these four variable are manufactured, so that a broader and clear picture can be achieved and more conclusive results can be drawn [12].

Three sets of these sixteen samples are analysed (Table 2). The term replicate is used for each set. A total of 48 samples are analysed. Each sample is identified by two numbers separated by a dot First number (1-3) 
Table 1. Variables and their different levels.

\begin{tabular}{cccc}
\hline Variable & Symbol & \multicolumn{2}{c}{ Level } \\
\hline Particle size & & 1 & 2 \\
Agitation & A & 2 & 10 \\
pH & B & Air & Stir \\
Surface treatment & C & 4.9 & 5.4 \\
\hline
\end{tabular}

Table 2. All sixteen possible combinations of the sample.

\begin{tabular}{cccc}
\hline Number & Combination & Number & Combination \\
\hline 1 & A1B1C1D1 & 9 & A1B2C2D1 \\
2 & A2B1C1D1 & 10 & A1B2C1D2 \\
3 & A1B2C1D1 & 11 & A1B1C2D2 \\
4 & A1B1C2D1 & 12 & A2B2C2D1 \\
5 & A1B1C1D2 & 13 & A1B2C2D2 \\
6 & A2B2C1D1 & 14 & A2B1C2D2 \\
7 & A2B1C2D1 & 15 & A2B2C1D2 \\
8 & A2B1C1D2 & 16 & A2B2C2D2 \\
\hline
\end{tabular}

represents which replicate sample is from, while the second number (1-16) represent the combination, for example Sample 1.15 means sample is from replicate 1 and combination 15 (A2B2C1D2).

\subsection{Cutting of the Samples}

Samples are in the form of squares of dimensions $25 \times 25 \mathrm{~mm}$. So they are cut in to $10 \times 10 \mathrm{~mm}$ dimensions with the help of pencil type Diamond scriber. initially tungsten carbide scriber was used but the Alumina tile was too hard for that, because both has hardness of 9.0 on Moh's hardness scale [13], so even harder material i.e. diamond is used as scriber which has hardness 10 on Moh's scale [13]. While samples are cut, special care is taken that the scriber draw a straight line and it don't scratch the surface of the sample, because if a scratch is present on the surface then that will act as a pore and result in the increase in the porosity of the material (Figure 1(a) and Figure 1(b)).

\subsection{Grinding}

Once all the samples are cut they are then grinded on Metaserve hard grinder using grit of 120,400,800 and 1200 microns respectively. The purpose of grinding is to balance the edges and give the samples more uniform dimensions and reduce the possibility of error because of irregular dimensions.

\subsection{Heating}

Samples are then heated in oven at $100^{\circ} \mathrm{C}$ for three hours to remove the water which has come in contact with the sample during grinding and also the moisture which is absorbed from atmosphere. Sanyo OMT oven is used for this purpose. They are then wrapped in paper and kept in the desiccator. It is essential to remove the moisture or any other impurity from the surface of the sample because if the pores are already occupied by the impurities then intruding liquids used in porosimetry cannot enter the pores, which will gives lower porosity then the actual one. All the identification markings of the samples are also removed using acetone, because ink of the writing 

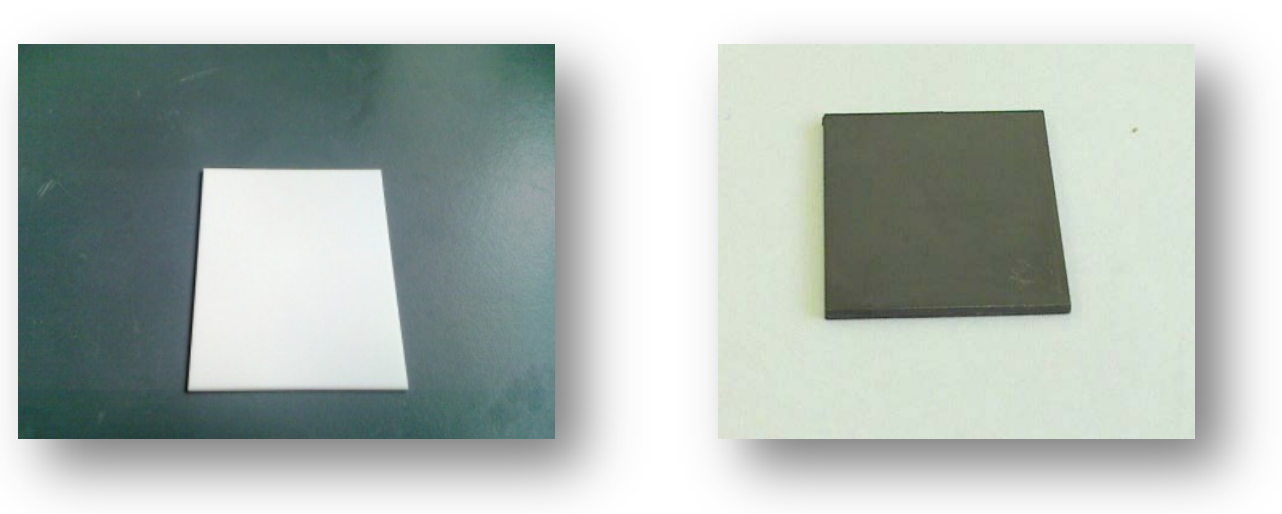

Figure 1. (a) Alumina tile; (b) Ni/YSZ coated sample.

can also reside in the pores thus barring intrusion medium to enter the pores during analysis.

Same procedure is followed for alumina tile which is acting as a substrate material. Here it should be noted that alumina is used instead of YSZ as substrate material for Ni/YSZ coating, because of the low price of Alumina and similarities of properties as both being dense ceramics.

\section{Experimental Density Calculation}

In this method first weight of composite is measured in air, then weight in water is measured by wrapping the sample in cling film and hanging the sample through a thin piece of metal wire in a beaker filled with distilled water. Weights are measured in Oertling NA 164 balance with values up to four decimal places. These weights are then used to calculate the density using the Archimedean formula.

$$
\rho_{\text {comp }}=M_{\text {air }} / M_{\text {air }}-M_{\text {water }}
$$

where

$$
\rho=\text { Density }
$$

And

$$
M=\text { mass }
$$

Similar process is repeated for alumina tile to calculate its density. Density of alumina is repeated five times and means value is used. Once density of alumina tile and sample are calculated then rule of mixture is applied to calculate the density of the coating.

$$
\rho_{\text {comp }}=\rho_{a} V_{a}+p_{c o t} V_{c o t}
$$

where

$$
\begin{gathered}
V_{a}=v_{a} / v_{c o m} \\
V_{c o t}=v_{c o t} / v_{c o m}
\end{gathered}
$$

where " $V$ " represents volume fraction and " $v$ " represents only volume. By putting all these values in Equation (2) we will get the experimental density of the coating.

\section{Theoretical Density Calculation}

After calculating experimental density, theoretical density is calculated. As the coating is made up of Ni and YSZ so theoretical density is calculated by using the rule of mixture

$$
\rho_{c o t}=\rho_{\mathrm{Ni}} V_{\mathrm{Ni}}+p_{y s z} V_{y s z}
$$

Density of $\mathrm{Ni}$ is $8.9 \mathrm{gm} / \mathrm{cm}^{3}$ while that of YSZ is $6.10 \mathrm{gm} / \mathrm{cm}^{3}$. These values are taken from literature. Now for volume fraction we must know the volume of each constituent. For that the samples are analyzed under the SEM and elemental analysis is carried out, which gave the percentage weight of each constituent. That weight 
percentage is then converted in to volume percentage and then further in to volume fraction. Weight percentage $\mathrm{Ni}$ content in all samples is given in Appendix 6(a)-(c). By putting all these values in Equation (3) theoretical density of Coating is calculated. The difference in theoretical density value and experimental density value is because of porosity which is calculated by formula given below;

$$
\begin{gathered}
\Phi=\left(\rho_{t h}-\rho_{\text {exp }} / \rho_{t h}\right) \times 100 \\
\Phi=\text { percent porosity } \\
\rho_{t h}=\text { Theoratical density } \\
\rho_{\text {exp }}=\text { Experimental density }
\end{gathered}
$$

For better understanding of the method, complete calculation of one representative sample is given here.

\section{Example \\ Sample}

Weight of sample in air $=0.4335 \mathrm{gm}$

Weight in water $=0.3177 \mathrm{gm}$

Put these values in Equation (1)

$$
\begin{gathered}
\rho_{\text {comp }}=0.4335 / 0.4335-0.3177 \\
\rho_{\text {comp }}=3.74 \mathrm{gm} / \mathrm{cm}^{3}
\end{gathered}
$$

Similarly density of alumina comes out $3.74 \mathrm{gm} / \mathrm{cm}^{3}$. This is a mean value of five alumina samples given in Appendix 5(b).

$$
\begin{gathered}
\text { Dimensions of the sample }=(1.105 \times 1.053 \times 0.098) \mathrm{cm}^{3} \\
\text { Volume of samle }=0.1140 \mathrm{~cm}^{3} \\
\text { Volume of coating }=0.000226 \mathrm{~cm}^{3} \\
\text { Volme fraction of coating }=0.000226 / 0.1140=0.00198 \\
\text { Volume fraction of Alumina }=1-0.00198=0.99802
\end{gathered}
$$

Put all these values in Equation (2)

$$
\begin{gathered}
3.74=3.74 \times 0.99802+0.00198 \times \rho_{\text {cot }} \\
\rho_{c o t}=3.74 \mathrm{gm} / \mathrm{cm}^{3}
\end{gathered}
$$

To calculate the theoretical density elemental percentage of all the constituent element is required which is calculated by SEM (Figure 2 and Table 3 ).

$$
\begin{gathered}
W t \% \text { age of } \mathrm{Ni}=81.92 \% \\
W t \% \text { age of } \mathrm{YSZ}=18.08 \%
\end{gathered}
$$

These weight percentages are converted in volume by dividing them with density.

$$
\begin{gathered}
\text { Volume of Nickel }=81.92 / 8.9=9.2045 \mathrm{~cm}^{3} \\
\text { Volume of } \mathrm{YSZ}=18.08 / 6.10=2.9639 \mathrm{~cm}^{3} \\
\text { Total volume of the coating }=9.2045+2.9639=12.1684 \mathrm{~cm}^{3} \\
\text { Volume fraction of } \mathrm{Ni}=9.2045 / 12.1684=0.7564 \\
\text { Volume fraction of } \mathrm{YSZ}=1-0.7564=0.2463
\end{gathered}
$$

Put these values in Equation (3) 


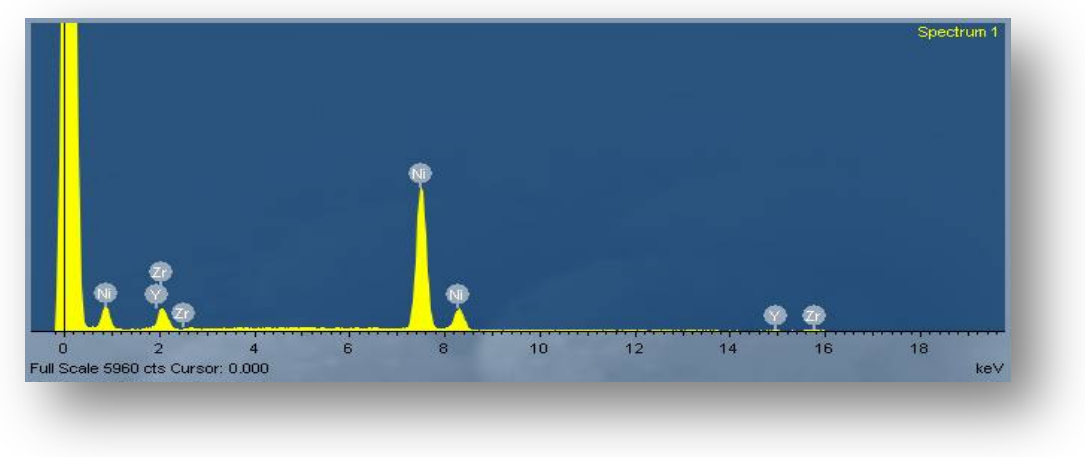

Figure 2. EDXA spectrum of $\mathrm{Ni} / \mathrm{YSZ}$ anode.

Table 3. Elemental analysis of Ni/YSZ anode from SEM.

\begin{tabular}{lccc}
\hline Element & Weight \% & Atomic \% \\
\hline & Ni K & & \\
Y L & 81.92 & 90.46 \\
Zr L & 3.43 & 1.85 & 7.69 \\
& & 14.65 & 100.00 \\
\hline
\end{tabular}

$$
\begin{gathered}
\rho_{\text {cot }}=8.9 \times 0.7564+6.1 \times 0.2463 \\
\rho_{\text {cot }}=8.218 \mathrm{gm} / \mathrm{cm}^{3}
\end{gathered}
$$

Now we know the theoretical density and experimental density, putting these values in Equation (4) we get the percent porosity of the coating

$$
\begin{gathered}
\Phi=(8.218-3.74 / 8.218) \times 100 \\
\Phi=54.49 \%
\end{gathered}
$$

This method is tried on ten different samples; results are discussed in chapter 4.

\section{Results and Discussion}

These results are beyond rational limits, giving negative and above 100 percent porosity simultaneously. The reasons for these unacceptable results are either water ingress into the sample or the sample became too buoyant due to air in the cling film. Therefore a different approach has to be adopted

\subsection{Relation between Thickness and Porosity}

Results obtained from this approach are quite encouraging and revealed some very important information. For replicates carried out on Archimedean Porosity a general trend is observed between coating thickness and porosity as shown in Figure 3 and Figure 4. The trend is that in water Archimedean porosimetry higher the porosity lower will be coating thickness and vice versa Perhaps this trend could be because at high porosity there are less growth sites available for the coating to grow on, while for thicker coating more active growth sites are available which encourages the coating to grow and in that growth it sometimes covers the pores in their path thus closing the open pores. A technique used here only measures the open porosity so these pores are not detected and gave lower percentage porosity. 

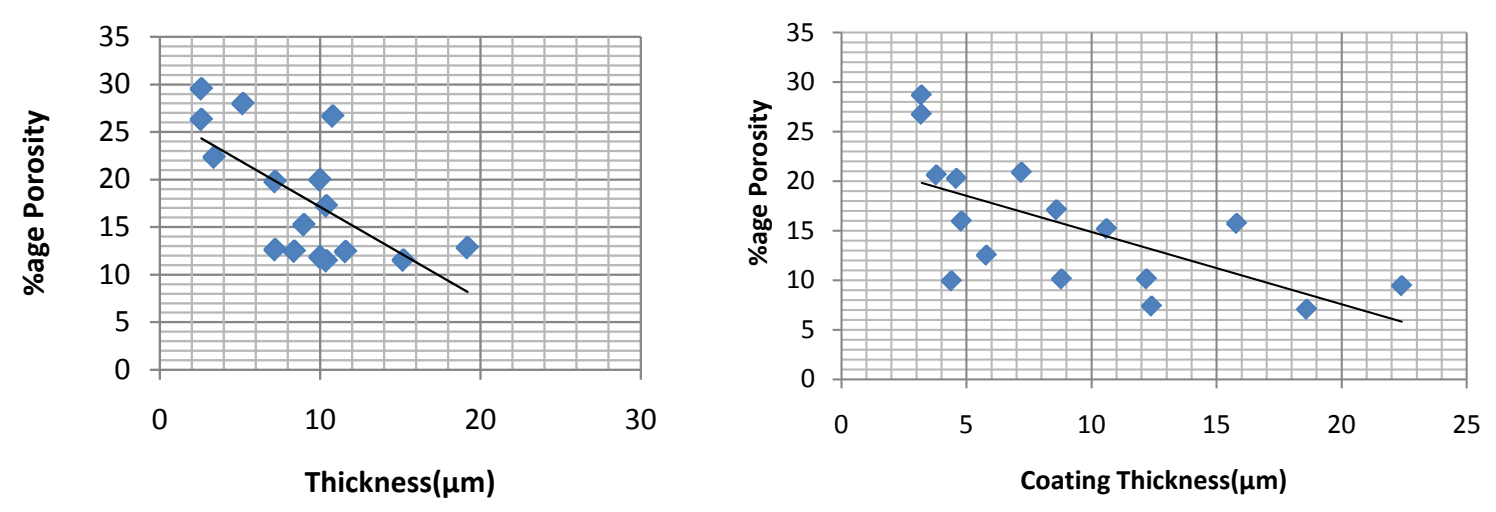

Figure 3. Graph thickness vs. percentage porosity.

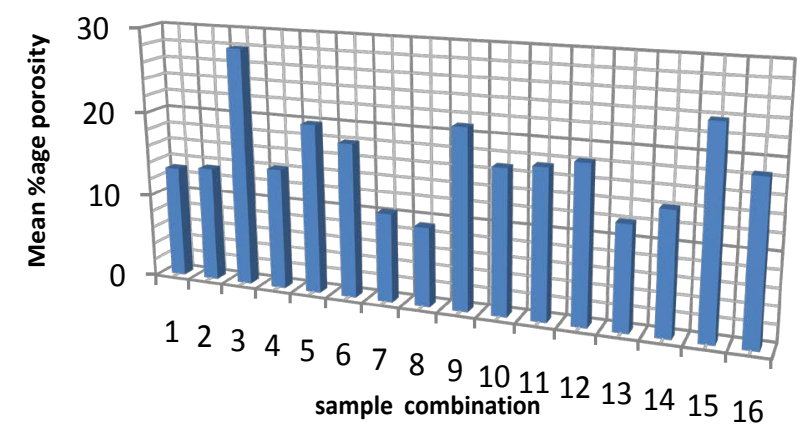

Figure 4. Comparison of mean porosities of two replicates measured.

\subsection{Optimum Set of Variable}

To analyse the optimum set of variables a bar graph is plotted by taking the mean porosities of all three replicates through water Archimedean porosimetry. Among all the three replicate it is observed that combination 3 and combination 15 always gave the highest porosities, as predictable the thickness of these combinations are among lowest. On observing the thickness it is revealed that combination 15 of replicate 1 has thickness a lot higher than for the same combination of other two replicates, which resulted in its low porosity.

\section{Combination $3=A 1 B 2 C 1 D 1$}

Combination $15=A 2 B 2 C 1 D 2$

It can be seen that both values of $\mathrm{A}$ and $\mathrm{D}$ gave high porosity, so they are not the ones which actually contribute in increasing the porosity.B2 and $\mathrm{C} 1$ these are the variables which are involve in both combination. so it can be inferred that whenever $\mathrm{B} 2$ and $\mathrm{C} 1$ are used with any combination of $\mathrm{A}$ and $\mathrm{D}$ we will get high porosity. In literal meaning when bath $\mathrm{pH}$ is low and stirrer used as agitator with any combination of particle size and surface treatment we will get the high porosity, hence these are e the optimum set of variables for porosity of SOFC anode made by electro less deposition.

\section{Conclusion}

Porosities of SOFC anodes made by electro less deposition are successfully calculated by water Archimedean porosimetry. In electro less deposition anodes made with bath $\mathrm{pH} 4.9$ and stirrer used as agitator gives the maximum porosity the particle size and surface treatment may have any value. A general rule is established which gives you an idea about porosity qualitatively. Porosity is inversely proportional to coating thickness. Results from water Archimedean porosimetry should only be used qualitatively due to errors associated with the results. AP is not the ideal technique for measuring the porosity of coated samples. 


\section{References}

[1] Davidson, A.M. and Waugh, W. (2008) Method of Manufacturing of an Electrode for Fuel Cell. New International (PCT) Patent Application Claiming Priority from U.K. Application No. 0719260.2.

[2] Duncan, R.C. (2005-2006) The Social Contract, the Olduvai Theory Energy, Population, and Industrial Civilization.

[3] Sayigh, A. (2009) Worldwide Progress in Renewable Energy.

[4] Kelly. M.J. (2010) Energy Efficiency, Resilience to Future Climates and Long-Term Sustainability: The Role of the Built Environment. Philosophical Transactions of the Royal Society A, 368, 1083-1089.

[5] EIA U.S. Energy Administration Independent Statistics and Analysis. http://tonto.eia.doe.gov/energyexplained/index.cfm?page=about energy units

[6] Bradley, J. (2010) The Scotsman, North Sea Oil Discovery.

[7] Boudghene, A. and Traversa, S.E. (2002) Solid Oxide Fuel Cells (SOFCs): A Review of an Environmentally Clean and Efficient Source of Energy. Renewable and Sustainable Energy Reviews, 6, 433-455

[8] Cleveland, C.J. Encyclopaedia of Energy. Vol. 1, Elsevier Academic Press, 151, 158-160.

[9] O’ Hayre, R., Cha, S.-W., Colella, W. and Prinz, F.B. (2006) Fuel Cell Fundamentals. John Willie and Sons.

[10] www.lifeaftertheoilcrash.net

[11] King, B. (2007) Bakhtiari's Event of the Century. Whiskey \& Gunpowder, Pittsburgh.

[12] Davidson, A. Lecture Notes.

[13] READE Speciality Chemical Resource. www.reade.com/Particle_Briefings/mohs hardness_abrasive_grit.html 